REVIEW ARTICLE

\title{
Can neuroimaging help combat the opioid epidemic? A systematic review of clinical and pharmacological challenge fMRI studies with recommendations for future research
}

\author{
Hestia Moningka ${ }^{1}$, Sarah Lichenstein ${ }^{2}$, Patrick D. Worhunsky ${ }^{1}$, Elise E. DeVito ${ }^{1}$, Dustin Scheinost ${ }^{2}$ and Sarah W. Yip ${ }^{1}$
}

The current opioid epidemic is an urgent public health problem, with enormous individual, societal, and healthcare costs. Despite effective, evidence-based treatments, there is significant individual variability in treatment responses and relapse rates are high. In addition, the neurobiology of opioid-use disorder (OUD) and its treatment is not well understood. This review synthesizes published fMRI literature relevant to OUD, with an emphasis on findings related to opioid medications and treatment, and proposes areas for further research. We conducted a systematic literature review of Medline and Psychinfo to identify (i) fMRI studies comparing OUD and control participants; (ii) studies related to medication, treatment, abstinence or withdrawal effects in OUD; and (iii) studies involving manipulation of the opioid system in healthy individuals. Following application of exclusionary criteria (e.g., insufficient sample size), 45 studies were retained comprising data from 1400 individuals. We found convergent evidence that individuals with OUD display widespread heightened neural activation to heroin cues. This pattern is potentiated by heroin, attenuated by medication-assisted treatments for opioids, predicts treatment response, and is reduced following extended abstinence. Nonetheless, there is a paucity of literature examining neural characteristics of OUD and its treatment. We discuss limitations of extant research and identify critical areas for future neuroimaging studies, including the urgent need for studies examining prescription opioid users, assessing sex differences and utilizing a wider range of clinically relevant task-based fMRI paradigms across different stages of addiction.

Neuropsychopharmacology (2019) 44:259-273; https://doi.org/10.1038/s41386-018-0232-4

\section{INTRODUCTION}

Nonmedical opioid use is a major public health problem in the United States, with rates of opioid-use disorder (OUD), treatment admissions, and opioid-associated overdoses and deaths rising dramatically in recent years [1-3]. Both behavioral and pharmacological approaches have shown promise for treating OUD. In particular, methadone, buprenorphine, and naltrexone are recommended (NIDA/SAMHSA Blending Initiative [4]; [5]) widely used [6] forms of medication-assisted treatment $[7,8]$. However, there is substantial individual variability in treatment response, and data indicate high rates of relapse even over the short term [9-13]. Therefore, further research is urgently needed to identify both novel treatment targets and individual difference factors conferring vulnerability for relapse.

Functional magnetic resonance imaging (fMRI) allows for indirect assessment of brain function and has been used extensively to study addictions and their treatment. Extant data indicate that multiple brain regions interact in a dynamic manner to influence a range of complex cognitive processes relevant to drug addictions. In particular, prefrontal cortical (PFC) brain regions involved in cognitive-control and executive-functioning processes [14-17] are reciprocally connected with subcortical limbic neurocircuitry (e.g., striatum, amygdala) involved in reward and incentive-salience encoding [18-21]. These networks are altered among individuals with drug addictions [16, 22, 23], and emerging data suggest that both short-term treatment efficacy [24-27] and longer-term recovery [28-30] may depend on appropriate engagement of these systems [31-33]. However, these processes are incompletely understood, particularly within the context of OUD.

Similarly, while the neurochemical/pharmacologic effects of medication assisted treatments for OUD are relatively well characterized [34], less is known about the down-stream effects of these medications on functional responses in the brain. fMRI has the potential to provide invaluable insights into these processes. Despite this potential, effective translation of research findings into the clinical realm remains elusive [35]. To synthesize existing knowledge and facilitate effective translation of findings to real-world clinical settings, we aim to build upon recent reviews focused more broadly on fMRI findings across different substance use disorders [36, 37] and others focused more narrowly on resting-state fMRI in OUD [38-40] by examining published fMRI literature (both task-based and resting-state) relevant to OUD, with an emphasis on findings related to opioid medications and treatment outcomes, as well as proposing areas for further research. By delineating common and distinct neural mechanisms of OUD pathophysiology and treatment response, it may be possible to identify which individuals are most likely to benefit from different treatments, optimize existing therapeutic approaches to target neural and clinical features of OUD, and

${ }^{1}$ Department of Psychiatry, Yale School of Medicine, New Haven, CT 06510, USA and ${ }^{2}$ Yale School of Medicine, Radiology and Bioimaging Sciences, New Haven, CT 06510, USA Correspondence: Sarah W. Yip (sarah.yip@yale.edu)

Received: 12 July 2018 Revised: 11 September 2018 Accepted: 18 September 2018

Published online: 3 October 2018 
260

unveil novel neuroscience-informed interventions to combat the nationwide opioid epidemic [32, 35, 41].

\section{METHODS}

A systematic literature search of Medline and Psychinfo was conducted on September $18^{\text {th }}, 2017$ using the following parameters: "fmri" and "heroin" or "opioid" or "opiate" or "buprenorphine" or "methadone" or "fentanyl". Our initial search yielded 157 studies. For simplicity, we categorized studies based on clinical relevance, as follows: (a) fMRI studies comparing OUD and control participants; (b) studies related to medication, treatment, abstinence or withdrawal effects in OUD (no control group required); and (c) studies involving manipulation of the opioid system in healthy individuals (no OUD group required Fig. 1). Studies not falling into one of these four categories (e.g., studies involving manipulation of the opioid system in alcohol-use disorder) were excluded.

Following exclusion of duplicate citations, manuscripts judged not to be relevant given the above criteria (based on titles and abstracts as necessary), or not to contain original, peer-reviewed research (e.g., reviews, book chapters), 69 studies were retained for full-text review. For between-group studies, we required a sample size of $n \geq 15$ per group. However, given this review's focus on clinical translation, a more liberal threshold of $n \geq 10$ was used for studies employing a within-subjects design (e.g., before and after daily methadone) or directly investigating treatment/recovery mechanisms (e.g., comparison of OUD individuals with and without subsequent relapse). Following full text inspection, an additional eight studies were judged ineligible (e.g., studies of OUD patients not related to treatment and not including a control group) and twenty were excluded due to insufficient or not specified sample sizes. Four additional studies were identified from other sources (e.g., references in other manuscripts) resulting in a total of 45 studies included in the present review. Further details on study inclusion are shown in Supplemental Fig. 1 (CONSORT diagram).

Results and sample characteristics

Using the above criteria, we identified $32 \mathrm{fMRI}$ studies including opioid-dependent individuals and 13 studies involving manipulation of the opioid system in healthy controls, together comprising data from just over 1400 individuals (769 OUD; 646 controls). Neuroimaging methodologies (types of task, analysis approach) and clinical characteristics (e.g., abstinence duration, medication status) varied widely across studies. For studies including individuals with OUD $(n=32)$, this included 18 task-based studies and 14 resting state studies. The primary opioid of abuse was heroin in all but one study. No studies compared OUD individuals based on type of opioid (e.g., prescription vs. non-prescription opioid use). Seventeen (37.7\%) of the 45 above-reviewed studies included solely male participants, yet no study was comprised solely of women. Across all studies, only 208 (14.7\%) of participants were female; Fig. 1). None of the studies identified in our systematic review (including those excluded for sample size limitations) included sex comparisons. Tables 1-4 summarize primary study characteristics (sample size, sex, primary drug, study design) and findings. Table 5 summarizes clinical characteristics of OUD individuals included in these studies (medication status, length of heroin abstinence prior to the study, and the duration heroin use/dependence). To facilitate comparison of findings across studies, we have organized our review based on methodological similarity (i.e., type of fMRI task). Below, we review primary findings with an emphasis on those from studies related to treatment or abstinence.

Drug cue reactivity

Predominant theories regarding the neurobiological basis of addiction assert that extended substance use is associated with neuroadaptations linked to overvaluation of drug-related stimuli relative to natural rewards [23,42]. A number of task-based fMRI studies have therefore focused on neural response to heroinrelated stimuli among individuals with OUD [43-52] (Table 1). As expected, studies examining brain activation to heroin-related cues converge in reporting greater neural response among OUD participants $[48,49,53]$, although the scope of this finding varies across reports. Findings generally indicate widespread increases in neural activation to heroin cues in OUD, extending throughout parietal, limbic (e.g., amygdala, striatum, hippocampus, thalamus), frontal cortical (e.g., anterior cingulate, dorsolateral prefrontal cortex, orbitofrontal cortex) and midbrain regions [45, 48, 49]. As a whole, findings from cue reactivity studies of OUD are therefore largely consistent with those from the larger addiction literature.

Neural responses to drug cues further appear sensitive to manipulation of the opioid system. Using a within-subjects, crossover design, Walter and colleagues [43] demonstrated increased orbitofrontal activity (ROI-based analysis only) in response to drug cues following acute heroin (vs. saline) administration in individuals receiving heroin maintenance therapy. In contrast, findings of decreased activity within orbitofrontal, insular, amygdalar and hippocampal regions have been reported following daily methadone administration [46]. Similarly, existing data indicate that acute administration of both naltrexone (opioid antagonist) and buprenorphine (partial agonist) are associated with decreased subcortical activity (e.g., amygdala, striatum, hippocampus) to drug cues $[47,52]$.

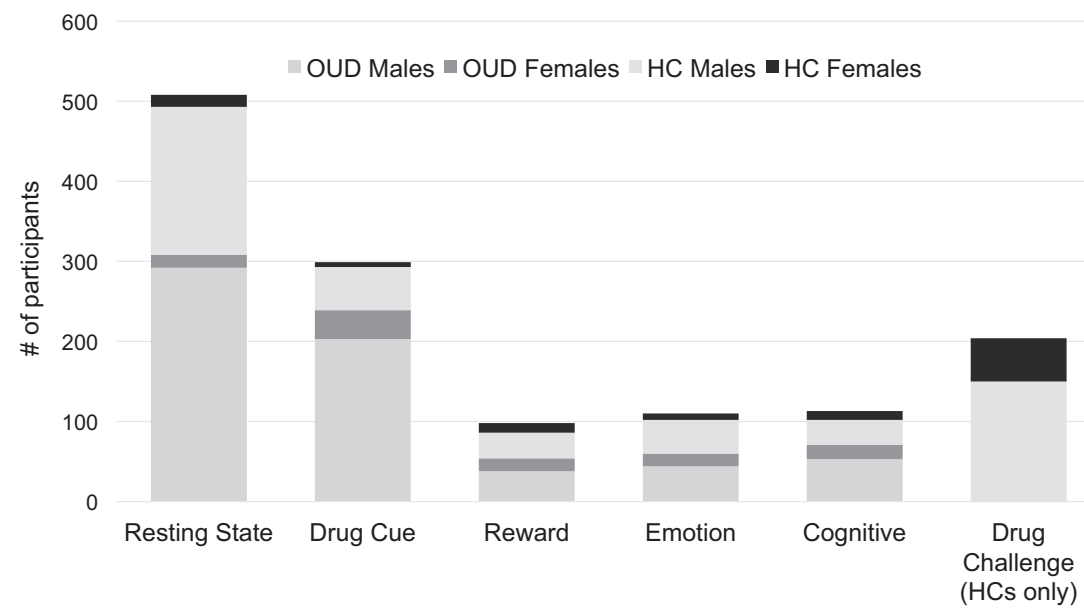

Fig. 1 Prevalence of male and female participants across reviewed fMRI studies. Across all studies, 208 (14.7\%) of participants were female 


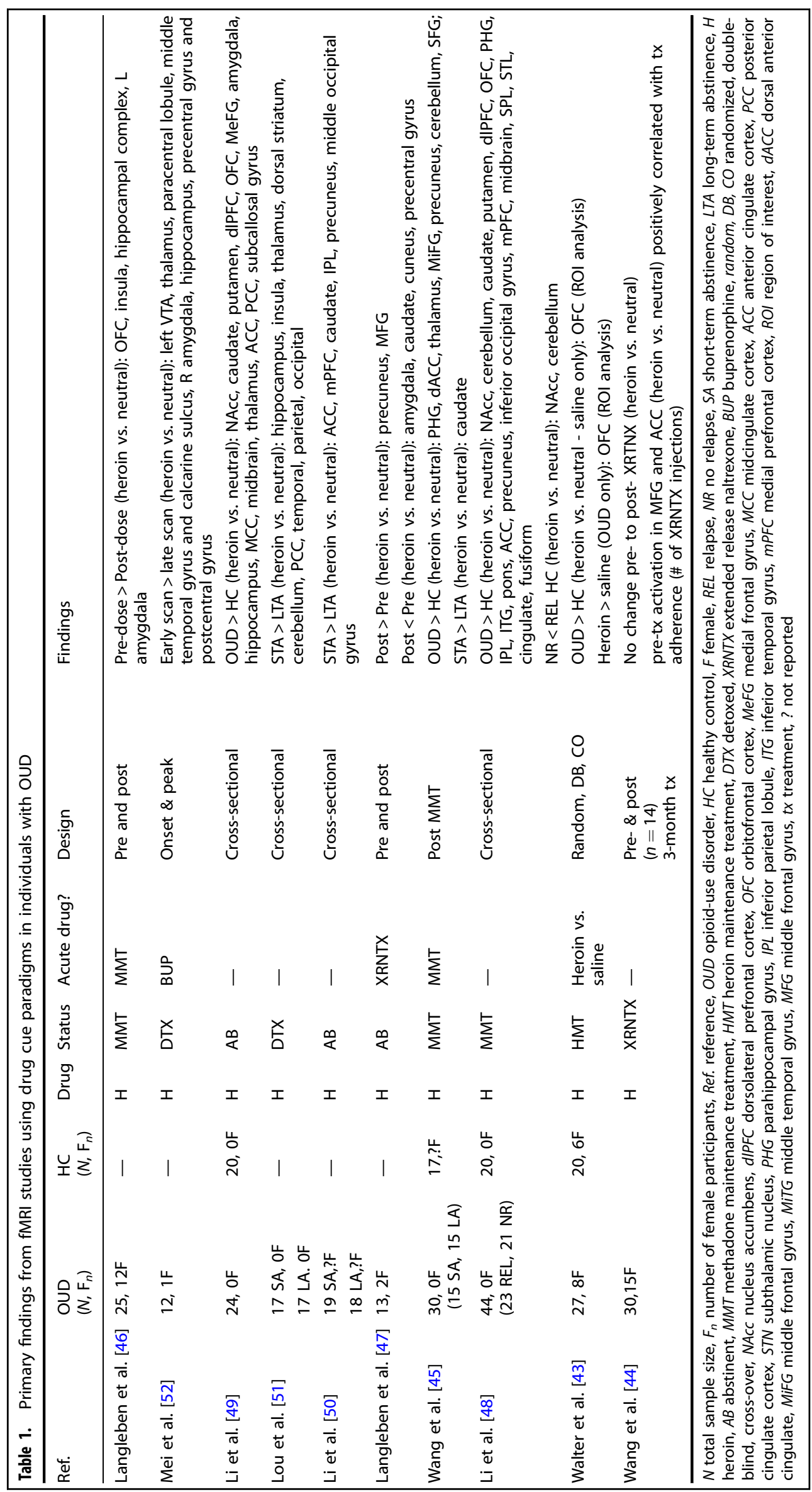




\section{2}

Neural responses to drug cues have also been shown to change following prolonged abstinence. Findings from cross-sectional studies comparing abstinence subgroups (e.g., short- vs. long-term abstinent patients) indicate that longer abstinence durations are associated with decreased striatal and other corticolimbic activity to drug cues, although the precise anatomical loci of these findings varied across studies [45, 50,51]. Similarly, prospective studies comparing baseline neural responses between individuals with and without a subsequent relapse indicate decreased striatal activity to heroin cues among non-relapsers [48]. Extant data therefore suggest that corticolimbic engagement to drug cues decreases with prolonged abstinence, and that individual differences in baseline reward responses to drug cues may contribute to variability in treatment response. However, longitudinal studies incorporating neuroimaging measures at multiple time points are needed to confirm these hypotheses.

Although somewhat varied across studies, findings from fMRI studies using drug cues to study OUD are generally consistent with current neurobiological theories of drug addictions: They indicate heightened engagement of corticolimbic neural circuitry to drug cues among current users relative to controls. In addition, existing data suggest that neural responses to drug cues are further increased following heroin administration, but are decreased following agonist (methadone), antagonist (naltrexone) or partial agonist (buprenorphine) medications [43, 46, 47, 52]. Thus, despite the differing pharmacological mechanisms of different forms of MATs (i.e., methadone vs. naltrexone vs. buprenorphine), these data raise the possibility of somewhat similar downstream effects of these medications on neural activity in response to drug cues. Finally, data from primarily crosssectional studies indicates that corticolimbic responses to drug cues may decrease following prolonged abstinence [45, 50,51]. Overall, these data support the hypothesis that brain regions involved in salience encoding and drug approach behaviors may be appropriate treatment targets for OUD interventions. However, further mechanistic work using longitudinal designs is needed to support this hypothesis.

Non-drug rewards

In contrast to typically heightened neural responses to drug cues, individuals with addictions typically exhibit blunted responses to non-drug rewards [54-56]. However, only two of the identified studies assessed reward processing in OUD using non-drug stimuli (Table 2). Using a reward/loss learning task Gradin and colleagues [57] observed decreased activity within regions including the dorsal caudate, insula, ventral striatum and inferior frontal gyrus among methadone-maintained individuals, relative to controls. Somewhat similar findings of decreased engagement within regions including the insula, inferior frontal gyrus, posterior cingulate and dorsolateral PFC have also been reported in a separate study of methadone-maintained individuals [58]. Thus, while somewhat limited, current data generally support the hypothesis that processing of non-drug rewards is diminished in methadonemaintained individuals. These data raise the possibility that adjunct treatments targeting reward mechanisms (e.g., contingency management, neurofeedback) might be beneficial in addressing residual reward processing deficits among methadone-treated individuals [35].

Both of the above-described studies reported interactions between methadone and reward responses, however anatomical loci and direction of associations differed across studies [57, 58]. Specifically, Gradin and colleagues reported positive associations between daily methadone dose and BOLD response within the midbrain and parahippocampal gyrus [57], whereas Yip and colleagues reported negative associations between daily methadone dose and BOLD response within the posterior cingulate and precuneus [58]. Furthermore, results from both studies diverge from a recent meta-analysis including individuals with alcohol, cocaine, 


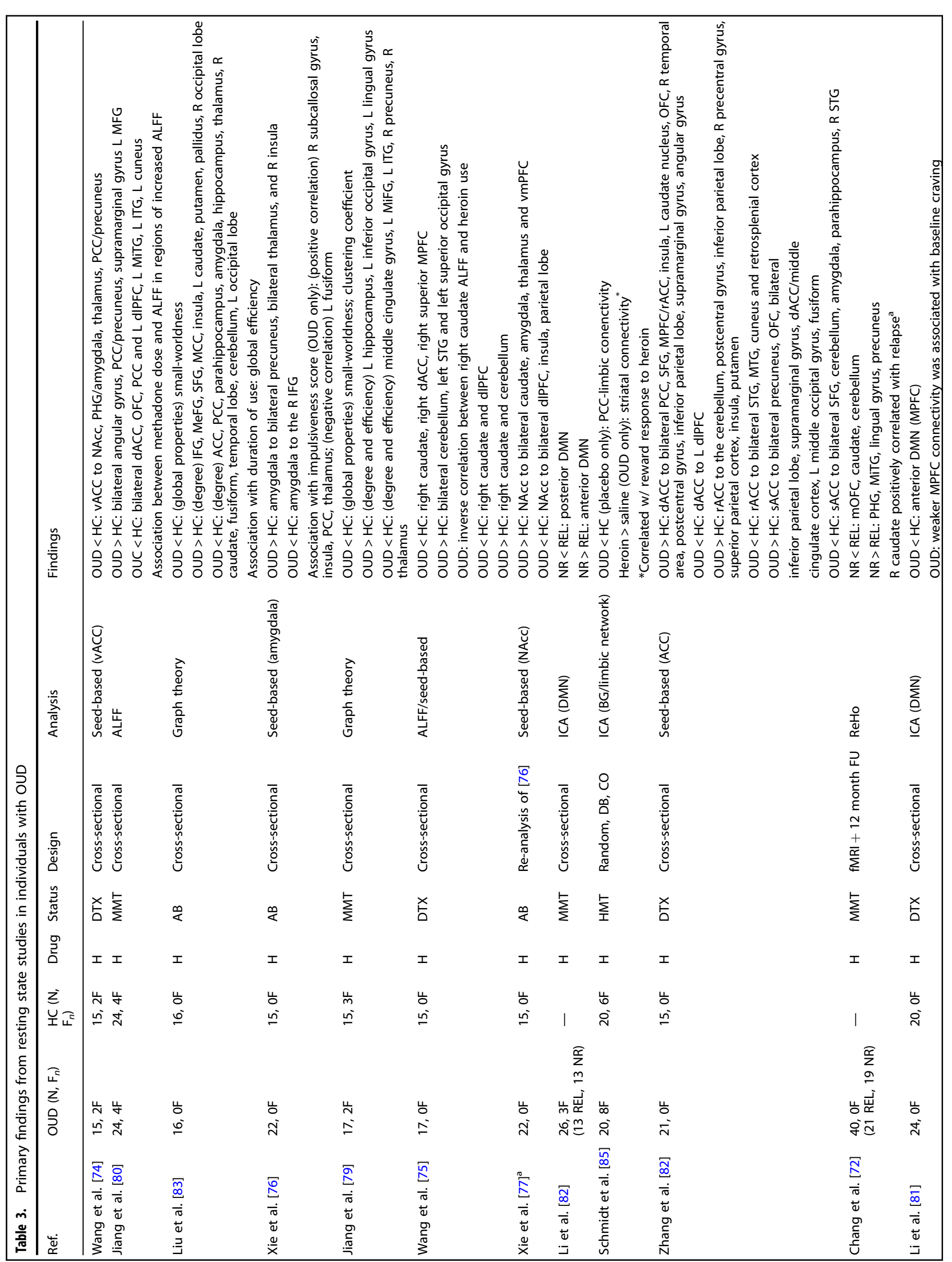


264

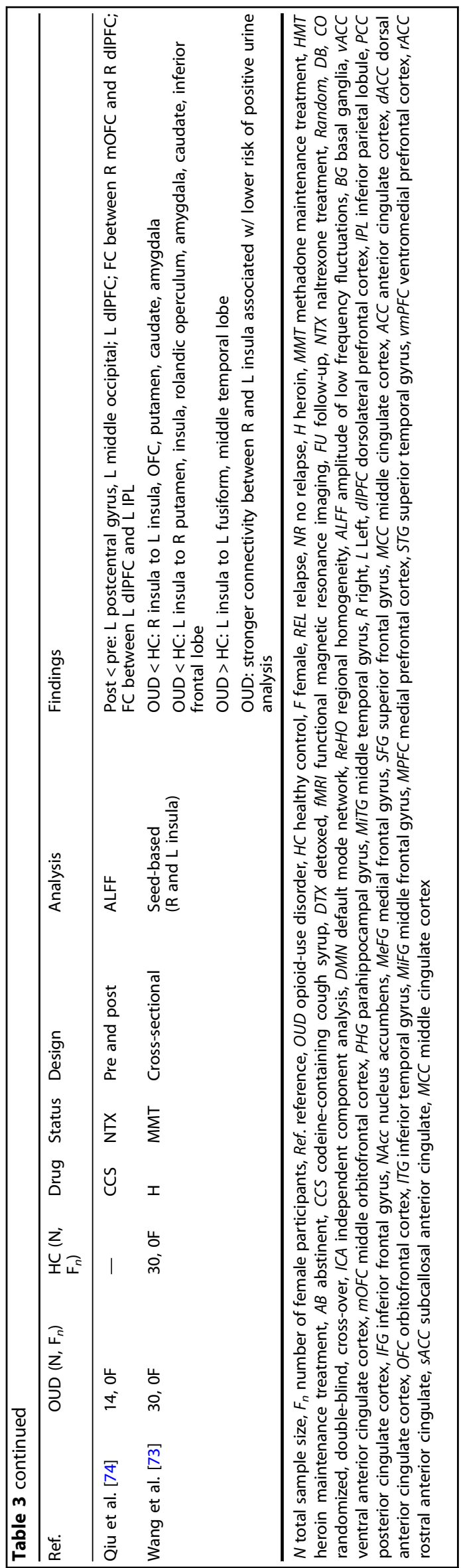

cannabis, nicotine, and gambling disorders, which reported increased activation of the ventral striatum, as well as frontal, cingulate, insular, parietal and occipital regions among addicted individuals relative to controls [59]. This discrepancy suggests that individuals with OUD may exhibit a distinct pattern of aberrant neural response to non-drug rewards compared to individuals with other substance-use disorders. Thus, while findings from both studies in OUD indicate residual alterations in reward processing of non-drug stimuli among methadone-treated individuals, further mechanistic work is needed to determine the specific effects of methadone on reward responses. Similarly, future studies are needed to determine the effects of naltrexone and buprenorphine on neural processing of non-drug rewards, particularly in light of existing data suggesting effects of these medications on processing of drug stimuli (reviewed above) [46, 47, 52].

\section{Affect processing}

Difficulties in emotion regulation, high rates of negative affect and alterations in processing of affective stimuli have been widely documented among individuals with addictions [60-62]. Overall, findings from studies of non-opioid addictions generally indicate reduced neural activation across a range of different regions in response to various emotional stimuli [37], and blunted amygdala responses to negative stimuli in particular [60, 61]. Consistent with this, a cross-sectional study of abstinent (inpatient) former heroin dependent individuals found decreased amygdala response in OUD individuals, relative to controls [63]. In contrast, using an ROI-based approach, Schmidt and colleagues [64] found an increased amygdala response to negative emotional faces among OUD patients receiving heroin maintenance therapy relative to controls, that was attenuated following acute heroin administration. Follow-up seed-based analyses in the same sample indicated increased connectivity between the fusiform (structure implicated in face processing) and amygdala that was also attenuated following heroin administration [65]. Thus, while extant data support the hypothesis of altered amygdala responses in OUD patients-and suggest sensitivity of these responses to opioid administration-the direction of findings overall remains equivocal (Table 2). Thus, further work across different patient groups (e.g., currently using, abstinent, medication-maintained individuals) is warranted. In addition, further work is needed to determine the extent to which alterations in amygdala reactivity may be specifically linked to emotion regulatory processes; e.g., as opposed to simply reflecting a more general blunting of neural responses to nondrug stimuli.

\section{Inhibitory control}

Response inhibition requires coordination of executive control processes and is central to models of addictive behavior $[66,67]$. Go/no-go tasks are widely used to study neural mechanisms underlying response inhibition and error processing. Studies conducted in healthy controls consistently report engagement of the anterior cingulate during go/no-go task performance [68]. Relative to control participants, data indicate decreased anterior cingulate, lateral PFC and insular engagement among individuals with OUD during go/no-go task performance [69]. Decreases in lateral PFC engagement during Go/no-go performance following acute heroin (vs. placebo) have further been demonstrated [70]. In contrast, data from Yücel and colleagues [71] indicate increased lateral PFC engagement, but no evidence for alterations in cingulate engagement, among OUD individuals relative to controls during performance of a multi-source interference task involving inhibitory control. This stands in contrast to literature on individuals with other substance use disorders, which have more consistently reported decreased 


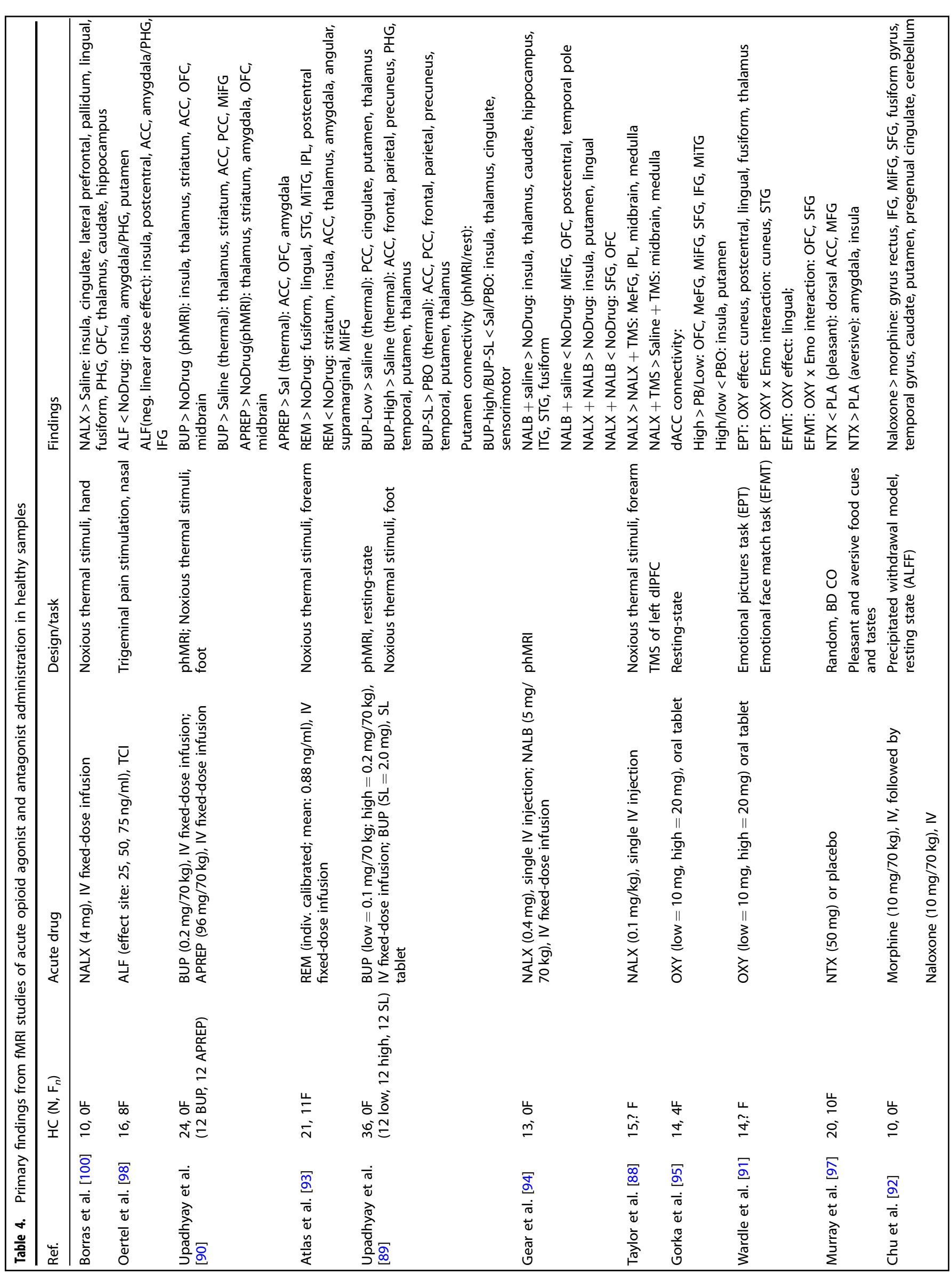


266 activation of cingulate, insular, and frontal regions during inhibitory control [37]. As with findings from other task domains shown in Table 2 (non-drug reward processing, affective processing), findings from studies of inhibitory control in OUD individuals remain conflicting and the relationship between inhibitory control processes and clinical features of OUD remains unknown. Thus, further work across diverse OUD populations is urgently needed to identify targets for improved prevention and intervention efforts.

\section{Resting state}

In contrast to task-based fMRI studies, resting-state studies of OUD individuals aim to characterize differences in the "intrinsic" organization of the brain via analysis of spontaneous fluctuations in the fMRI signal while the brain is "at-rest"-i.e., in the absence of a task. Given the unconstrained nature of resting-state data, many different methods have been proposed for analysis. This methodological variability is reflected in the resting-state studies of OUD individuals identified here, with few manuscripts using comparable methods. Table 3 summarizes all identified resting state studies [72-85]. Given the large range of diverse analysis methods employed, we here focus on primary findings from studies using similar analysis approaches.

Independent component analysis (ICA) is a network-based analysis approach for identifying temporally coherent functional networks. Three studies have used ICA to probe connectivity within canonical (e.g., default mode, limbic) networks among individuals with OUD. Using this approach, $\mathrm{Li}$ and colleagues reported decreased anterior default mode network (DMN) connectivity among recently detoxed, medication-free, heroin dependent individuals, relative to controls [81]. Similarly, an ICA study focusing on limbic network connectivity found decreased connectivity between the posterior cingulate (part of posterior default mode) and a limbic network among heroin-maintained patients relative to controls, despite no between-group differences in within-network limbic connectivity [85]. A separate crosssectional study comparing OUD individuals as a function of relapse status reported increased anterior DMN connectivity-in addition to decreased posterior DMN connectivity-among abstinent vs. relapsed patients [82].

Findings from two studies using seed-based approaches (functional connectivity between one or more a priori ROIs) using the anterior cingulate as a seed further indicate connectivity alterations between brain regions consistent with the posterior DMN (posterior cingulate, precuneus, retrosplenial cortex), however these studies were inconsistent in whether OUD exhibited greater connectivity compared to controls [74, 78]. Thus, ICA studies collectively report a pattern of altered DMN connectivity among OUD individuals that is characterized by decreased anterior (e.g., mPFC) and increased posterior (e.g., posterior cingulate) connectivity, whereas studies employing seed-based approaches have yielded less consistent findings.

Other approaches employed in resting state studies of OUD include graph theory and amplitude of low frequency fluctuation (ALFF) analyses. Graph theory is a method to characterize global and regional properties of whole brain functional networks. Two graph theory studies reported reduced small worldness (property where brain regions cluster into segregated networks, but communication between these networks is efficient due to highly connected hub regions [86]) and degree (the number of connections to a brain region) in the cingulate cortex for OUD individuals compared to healthy controls $[79,83]$. ALFF is a method to quantify the amplitude of the power spectrum of the BOLD signal, and thus an indirect method for quantifying "spontaneous" neural activity. In two studies using this approach, consistent decreases in ALFF were observed in the dorsal ACC and in the DMN $[75,80]$ for OUD individuals compared to 
Table 5. Clinical characteristics of studies reviewed

\begin{tabular}{|c|c|c|c|c|}
\hline Ref & Recruitment route & MAT Status & $\begin{array}{l}\text { Abstinence duration prior } \\
\text { to study }\end{array}$ & $\begin{array}{l}\text { Duration of heroin use/ } \\
\text { dependence }\end{array}$ \\
\hline Langleben et al. [46] & MMT clinic in USA & $\begin{array}{l}\text { MMT } \\
54 \pm 33 \text { months }\end{array}$ & $16 \pm 13$ months & n.r. \\
\hline Mei et al. [52] & Inpatient DTX clinic in China & $\begin{array}{l}\text { DTX (scanned prior to TX or }>8 \mathrm{~h} \\
\text { after first BUP dose) }\end{array}$ & $50 \pm 24 h$ & $4.5 \pm 4.4$ years \\
\hline Li et al. [49] & Residential treatment in China & $A B$, no MAT & $21.7 \pm 16$ days & $78.6 \pm 50.1$ months \\
\hline Lou et al. [51] & Forced DTX center in China & DTX & $\begin{array}{l}\text { STA: } 1.2 \pm 0.1 \text { months } \\
\text { LTA: } 13.6 \pm 0.4 \text { months }\end{array}$ & $\begin{array}{l}\text { STA: } 7.0 \pm 1.0 \text { years } \\
\text { LTA: } 8.2 \pm 1.1 \text { years }\end{array}$ \\
\hline Li et al. [50] & Drug rehab center in China & AB (post-methadone-assisted DTX) & $\begin{array}{l}\text { STA: } 23.6 \pm 17.6 \text { days } \\
\text { LTA: } 193.3 \pm 42.7 \text { days }\end{array}$ & $\begin{array}{l}\text { STA: } 80.5 \pm 54.4 \text { months } \\
\text { LTA: } 96.3 \pm 69.5 \text { months }\end{array}$ \\
\hline Langleben et al. [47] & $\begin{array}{l}\text { Court mandated OUD TX (selected } \\
\text { XRNTX) in USA }\end{array}$ & $A B$ & $97 \pm 123$ days & $12.5 \pm 8$ years \\
\hline \multirow[t]{2}{*}{ Wang et al. [45] } & \multirow[t]{2}{*}{ MMT in China } & $\begin{array}{l}\text { MMT Group A: }<1 \text { year; } 7.92 \pm \\
2.89 \text { months }\end{array}$ & \multirow[t]{2}{*}{ n.r } & Group A: $48.6 \pm 49.9$ months \\
\hline & & $\begin{array}{l}\text { Group B: }>2 \text { years; } 29.62 \pm \\
3.53 \text { months }\end{array}$ & & Group B: $49.64 \pm 42.5$ months \\
\hline Li et al. [48] & MMT clinic in China & $\begin{array}{l}\text { MMT } \\
\text { Relapsers: } 18.3 \pm 11.5 \text { months } \\
\text { Non-relapsers: } 25.5 \pm 17.3 \text { months }\end{array}$ & n.r. & $\begin{array}{l}\text { Relapsers: } 69.2 \pm 68.5 \text { months } \\
\text { Non-relapsers: } 92.3 \pm \\
70.5 \text { months }\end{array}$ \\
\hline Walter et al. [43] & $\begin{array}{l}\text { Centre of Substance Use Disorders } \\
\text { in Switzerland }\end{array}$ & $\begin{array}{l}\text { HMT } \\
7.3 \pm 4.4 \text { years }\end{array}$ & $\mathrm{n} / \mathrm{a}$ & $21.1 \pm 5.7$ years \\
\hline Wang et al. [44] & Local ads in China & $\begin{array}{l}\text { Active users prior to enrollment, DTX } \\
\text { as part of study }\end{array}$ & $\mathrm{n} / \mathrm{a}$ & n.r. \\
\hline Gradin et al. [57] & NHS addiction service in UK & MMT $>6$ weeks at stable dose & n.r. & 3 year minimum \\
\hline Yip et al. [58] & $\begin{array}{l}\text { RCT of cocaine use disorder } \\
\text { treatment in USA MMT clinic }\end{array}$ & MMT $>2$ months at stable dose & n.r. & n.r. \\
\hline Wang et al. [63] & $\begin{array}{l}\text { Forced DTX program in China } \\
(2-5 \text { months post-DTX) }\end{array}$ & $A B$ & $3.4 \pm 0.9$ months & $6.9 \pm 2.9$ years \\
\hline $\begin{array}{l}\text { Schmidt et al. [64, } \\
65]\end{array}$ & $\begin{array}{l}\text { Centre of Substance Use Disorders } \\
\text { in Switzerland }\end{array}$ & $\begin{array}{l}\text { HMT > } 6 \text { months (>3 months at } \\
\text { stable dose) }\end{array}$ & $\mathrm{n} / \mathrm{a}$ & $21 \pm 6.4$ years \\
\hline Fu et al. [69] & $\begin{array}{l}\text { Inpatient abstinence treatment in } \\
\text { China }\end{array}$ & $A B$, no MAT & $7.64 \pm 2.16$ weeks & $6.25 \pm 3.53$ years \\
\hline Schmidt et al. [70] & $\begin{array}{l}\text { Centre of Substance Use Disorders } \\
\text { in Switzerland }\end{array}$ & $\begin{array}{l}\text { HMT }>6 \text { months ( }>3 \text { months at } \\
\text { stable dose) }\end{array}$ & $\mathrm{n} / \mathrm{a}$ & $20.54 \pm 6.56$ years \\
\hline Yucel et al. [71] & $\begin{array}{l}\text { Community treatment providers in } \\
\text { Australia }\end{array}$ & $\begin{array}{l}\text { MMT \& BMT } \\
31.54 \pm 32.55 \text { months }\end{array}$ & $24 \mathrm{~h}$ minimum & $107.44 \pm 60.87$ months \\
\hline Wang et al. [74] & Individuals seeking DTX in China & Active users prior to enrollment & $5.1 \pm 0.29 h$ & $19.9 \pm 3.1$ years \\
\hline Jiang et al. [80] & $\begin{array}{l}\text { Individuals seeking treatment in } \\
\text { China }\end{array}$ & $\begin{array}{l}\text { MMT } \\
6-7 \text { days }\end{array}$ & n.r. & $10.83 \pm 4.61$ years \\
\hline Liu et al. [83] & MMT clinic in China & $\begin{array}{l}\text { MMT } \\
\text { Duration n.r. }\end{array}$ & $4.76 \pm 0.7$ months & $85.3 \pm 46.2$ months \\
\hline Xie et al. [76] & Hospital in China & $A B$ & $8.05 \pm 2.51$ weeks & $6.59 \pm 3.72$ years \\
\hline Jiang et al. [79] & Hospital in China & $\begin{array}{l}\mathrm{MMT}^{\mathrm{a}} \\
\text { Duration n.r. } \\
2 \text { participants not on } \mathrm{MMT}^{\mathrm{a}}\end{array}$ & $6-7$ days & $9.21 \pm 5.28$ years \\
\hline Wang et al. [75] & MMT clinic in China & $\mathrm{AB}$ & n.r. & $81.5 \pm 33.9$ months \\
\hline Xie et al. [77] & Hospital in China & $A B$ & $8.05 \pm 2.51$ weeks & $6.59 \pm 3.72$ years \\
\hline Li et al. [82] & MMT clinic in China & MMT > 3 months at stable dose & n.r. & n.r. \\
\hline Schmidt et al. [85] & $\begin{array}{l}\text { Centre of Substance Use Disorders } \\
\text { in Switzerland }\end{array}$ & $\begin{array}{l}\text { HMT }>6 \text { months ( }>3 \text { months at } \\
\text { stable dose) }\end{array}$ & $\mathrm{n} / \mathrm{a}$ & $21.5 \pm 6.10$ years \\
\hline Zhang et al. [78] & Forced DTX program in China & $A B$ & $8.05 \pm 2.51$ weeks & $6.2 \pm 3.53$ years \\
\hline Chang et al. [72] & MMT clinic in China & MMT > 3 months & n.r. & $\begin{array}{l}\text { Non-relapsers: } 275.7 \pm \\
69.1 \text { months }\end{array}$ \\
\hline & & & & Relapsers: $224 \pm 64.5$ months \\
\hline Li et al. [81] & n.r. & $A B$ & $21.7 \pm 16$ days & $78.6 \pm 50.1$ months \\
\hline Qiu et al. [84] & Hospital in China & UROD + NMT & n.r. & $4.96 \pm 1.97$ years \\
\hline Wang et al. [73] & n.r. & MMT $>3$ months & $237 \pm 424.35$ days & $7.66 \pm 3.55$ years \\
\hline
\end{tabular}

Ref. reference, $M M T$ methadone maintenance treatment, USA United States of America, n.r. not reported, DTX detox, $T X$ treatment, $B U P$ buprenorphine, $A B$ abstinent, MAT medication-assisted therapy, STA short-term heroin abstinence, LTA long-term heroin abstinence, OUD opioid use disorder, XRNTX extended release naltrexone, $H M T$ heroin maintenance treatment, $n / a$ not applicable, NHS National Health Service, UK United Kingdom, $R C T$ randomized controlled trial, $B M T$ buprenorphine maintenance treatment, UROD general anesthesia, NMT naltrexone maintenance treatment 
268

healthy controls. However, the exact regions of the DMN and regions of increased ALFF were inconsistent across the two reports.

Preliminary data further indicate that resting state connectivity may be sensitive to manipulations of the opioid system: in a randomized, double-blind, cross-over study, Schmidt and colleagues [85] reported increases in striatal connectivity following acute heroin administration (vs. saline) that were positively related to subjective drug responses. In a separate within-subjects study, decreases in ALFF following naltrexone treatment (vs. baseline) were reported within primarily cortical regions including the medial OFC and DLPFC among codeine-dependent individuals [84]. Given the large number of methodological differences between these studies (e.g., drug, analysis approach, study population), further work directly comparing effects of opioid agonism vs. antagonism on resting state networks (in the same group of participants) is needed.

Across most studies, the DMN (including the PCC and mPFC) was consistently highlighted as exhibiting altered connectivity in OUD individuals relative to controls. However, the direction of these effects was varied. The discrepancy between the direction of DMN connectivity differences in OUD is likely influenced by the methodology used and the patient population being studied, making comparisons across studies difficult. Notable characteristics of study samples may also limit the generalizability of published results. For example, none of the identified studies were conducted in the United States, thus generalization of findings to the current demographically and clinically unique generation of opioid users in the United States may be limited [87]. Similarly, as with the majority of task-based studies, very few studies included female participants (see Fig. 1 for distribution of male and female participants across studies).

\section{Manipulation of the opioid system in healthy controls}

We identified 13 studies assessing the effects of opioidergic agents on brain activity in samples of healthy adults [88-100] (Table 4). A number of studies have examined the effects of opioid agonists and antagonists on brain responses to noxious stimuli in healthy individuals. Noxious or painful stimuli activate an established network of regions including the insula, anterior cingulate, thalamus, medial and lateral prefrontal areas, parietal cortex, striatal structures and somatosensory regions [101]. While specific patterns of brain activity may differ by modality (e.g., mechanical vs. thermal pain) [102], the effects of opioidergic agents on pain-related neural responses are largely consistent. Opioid agonists remifentanil and alfentanil reduced pain-related signaling in the thalamus, insula, cingulate, striatum, and sensorimotor regions [93, 96, 98]. By comparison, naloxone (antagonist) and buprenorphine (partial agonist) administration in healthy controls are associated with increased signaling across these regions in response to noxious stimuli $[89,90,100]$. In addition, naltrexone (antagonist) is associated with increased insula and amygdala activity to aversive food cues, but with decreased response within the dorsal anterior cingulate to appetitive food cues [97].

Several pharmacological fMRI (phfMRI) studies also characterized neural responses to opioidergic agents in the absence of stimuli. Compared to a no-drug condition, buprenorphine (partial agonist) and aprepitant (antiemetic) similarly increased neural signals in the striatum, midbrain, thalamus, and orbitofrontal cortex [90]. Both acute oxycodone and buprenorphine are further associated with reduced connectivity patterns between the insula and subcortical regions (e.g., thalamus, striatum) in healthy controls [89, 95]. Thus, phMRI findings suggest that, in the absence of stimuli, full (oxycodone) and partial (buprenorphine) opioid agonists appear to influence connectivity within a similar set of reward-related regions.

\section{DISCUSSION}

This systematic literature review identified $45 \mathrm{fMRI}$ studies relevant to OUD, together comprising data from $\sim 1400$ individuals. Perhaps not surprisingly, neuroimaging methodologies (task type, analysis method) and clinical features (abstinence duration, medication status) varied widely across studies. However, cumulative evidence did converge for some domains-most notably drug cue reactivity and, to a lesser extent, drug challenge studies. Below we summarize findings from key domains and recommend directions for future clinically oriented neuroimaging work to help combat the current opioid epidemic.

Consistent with predominant theories of addictions, data indicate relatively widespread increases within parietal (precuneus, posterior cingulate), limbic (amygdala, striatum, hippocampus, thalamus), frontal cortical (anterior cingulate, dorsolateral prefrontal cortex, orbitofrontal cortex) and midbrain regions among OUD individuals in response to drug cues [45, 48, 49]. Emerging data further suggest that individual differences in baseline neural responses to drug cues may be linked to differences in treatment outcomes, such that reduced responses are associated with longer abstinence durations $[45,50,51]$. While replication of this latter finding in larger samples is required, these data raise the possibility that therapies specifically targeting neural responses to drug cues (e.g., cognitive bias modification; real time fMRI) might be effective adjuncts to existing therapies [31, 103, 104].

Findings from other domains (i.e., non-drug reward processing, affect processing, inhibitory control) have been far less consistent. This is likely due to the relative dearth of studies conducted in these domains (8 studies over three domains), as the overwhelming majority of identified OUD fMRI studies either utilized drug-cue paradigms or else assessed the brain "at rest". Furthermore, discrepancies in the specific tasks used and the analytic frameworks employed may also contribute to inconsistent patterns of results across studies. Thus, further work characterizing the functional neurobiology of OUD across other clinically relevant domains is urgently needed. In particular, task-based fMRI studies using standardized paradigms, which can be applied across species and analyzed using computational and cognitive modeling approaches, will help to elucidate the nature of cognitive and affective neural functioning in OUD.

Findings from resting-state studies generally support the hypothesis of altered DMN engagement among individuals with OUD, although the direction of these alterations has not been consistent across studies. As noted above, the identified resting state studies included a large number of methodological limitations, making interpretation of findings across studies problematic. In particular, given the variety of analysis methods employed (e.g., ALFF, ICA), the virtual absence of whole-brain analyses, and the relatively short durations of image acquisitions (e.g., $\sim 5 \mathrm{~min}$ ), collective findings from extant resting state analyses should be interpreted with caution. Thus, both acquisition of more data (i.e., longer durations) per subject (to improve within-subject reliability) and harmonization of analysis approaches and data pooling across studies are strongly recommended as important future directions for resting-state work in OUD populations [105$110]$. As resting state analyses are particularly sensitive to motion effects, future studies should also incorporate more sophisticated motion correction techniques [111, 112] and test for possible effects of between-group (i.e., patients vs. controls) differences in motion on connectivity patterns.

Figure 2 summarizes primary findings from selected brain regions for studies involving manipulation of the opioid system (further details in Supplemental Table 1). Combined data generally indicate somewhat similar effects of opioid agonism in healthy controls and individuals with OUD (Fig. 2). For example, administration of both acute methadone (in patients) and oxycodone (in controls) is associated with decreases in neural 


\section{$\begin{array}{lll}\text { OFC INS } & \text { OHIP } \\ \text { AMY OACC } & \text { IFG }\end{array}$ \\ THA OSTR OMBN \\ SMT}

\section{OUD \\ INCREASE MIXED \\ DECREASE NS}
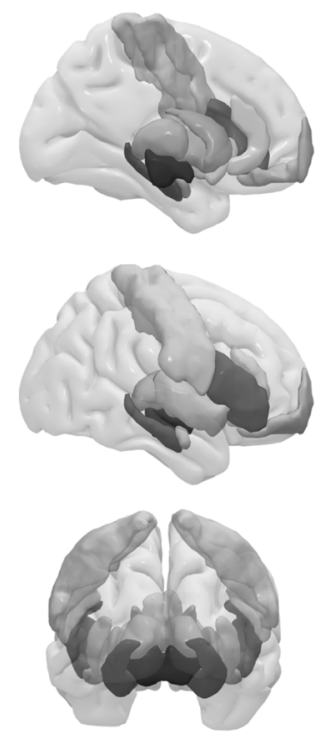

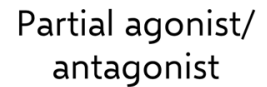

Agonist
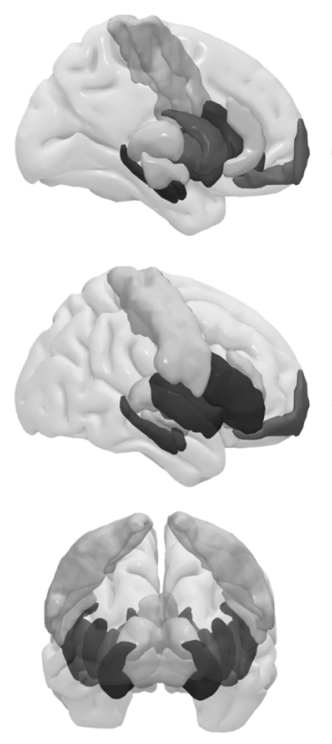
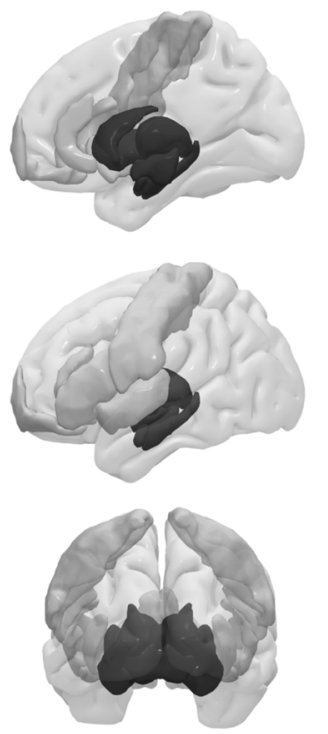

Agonist

Partial agonist/ antagonist
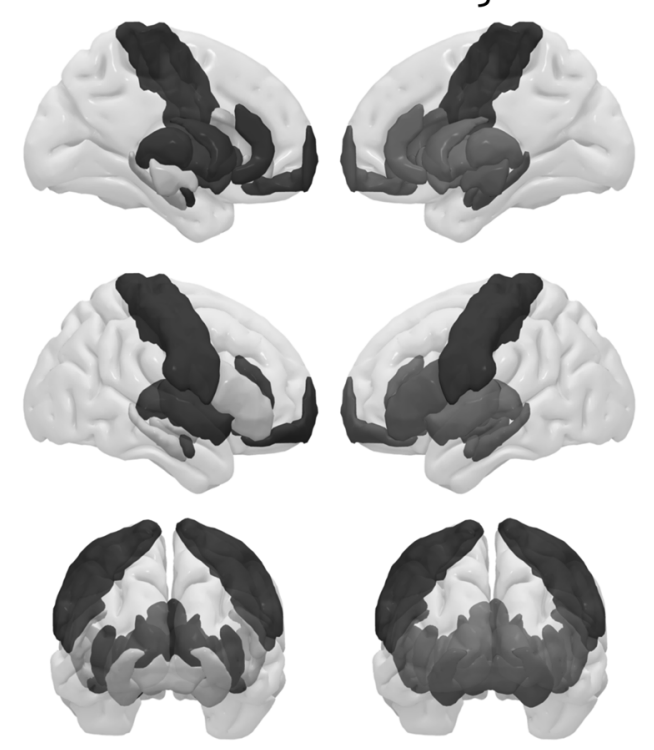

Fig. 2 Regional effects of opioidergic agents on neural function. Summarizes primary findings for selected brain regions from fMRI studies involving manipulation of the opioid system. OFC orbitofrontal cortex, INS insula, HIP hippocampus, AMY amygdala, ACC anterior cingulate, IFG inferior frontal gyrus, THA thalamus, STR striatum, MBN midbrain, SMT sensorimotor, OUD opioid use disorder, HC healthy control, NS no results. Based on data reported in refs [43, 46, 47, 52, 64, 70, 85, 89-91, 93-98, 100]. For studies including multiple conditions, e.g., ref. [89], results reported for neutral or resting state conditions were used for figure generation (see Supplemental Table 1 for details). Refer to Tables 1-4 of the primary manuscript for additional summaries of study findings

responses within the OFC and limbic regions $[46,95]$. In contrast, acute heroin administration (in patients) is associated with increases in OFC and striatal regions. In addition, both antagonist (naltrexone) and partial agonist (buprenorphine) administration have been associated with relative decreases within limbic regions in studies of OUD individuals $[47,52]$, whereas findings on the effects of buprenorphine administration (during resting state) in controls have been mixed [89, 90]. Somewhat contrastingly, buprenorphine (partial agonist) and naloxone (antagonist) administration have also been associated with increased activity within the thalamus, insula, cingulate and striatum when paired with noxious stimuli in healthy controls $[89,90,100]$. Notably, none of the studies conducted in OUD individuals meeting our inclusionary criteria utilized noxious stimuli/assessed pain response. Given the very high prevalence rates of chronic pain among patients entering MAT [113], work in this area is urgently needed.

Despite the apparent relative concordance across some pharmaco-fMRI studies of OUD individuals and controls, numerous between-study methodological differences make direct comparison of findings problematic. For example, while several of the studies conducted in OUD employed randomized, double-blind, cross-over designs ("gold standard" for pharmacological challenge research), very few conducted in controls have done the same. Thus, further work to disentangle actual drug effects from those of expectation (placebo) effects, particularly among healthy individuals, is needed. In addition, no studies have controlled for possible medication-induced changes in metabolism, blood flow, and neurovascular coupling. Given that each of these factors can modulate the fMRI signal [114-116] and potentially lead to mischaracterization of neural activity, future studies also incorporating cerebral perfusion measures (e.g., pulsed arterial spin labeling) [117] are needed to better characterize the effects of opioidergic agents on neural activity across patients and controls.
Over the past two decades there has been a dramatic shift in opioid use initiation [87], with the overwhelming majority of heroin users also reporting prior misuse of prescription opioids [118]. Despite this, heroin was the primary opioid of abuse across all but one fMRI study, which studied codeine-dependent individuals [84]. As increases in prescription opioid abuse have occurred in tandem with changes in clinical and demographic features of individuals seeking treatment for OUD [87], future fMRI work specifically assessing the neural correlates of prescription opioid use and abuse (vs. heroin use) is urgently needed.

Need for consideration of sex as a biological variable in studies of OUD

The overall inclusion of women was very low across reviewed studies ( $<15 \%$ of all participants; Fig. 1$)$ and no study included consideration of sex differences. This is part of a larger problem of underrepresentation of women and insufficient consideration of sex in clinical research more generally and addiction research specifically [119]. Sex differences have been demonstrated in the rates and clinical characteristics of individuals with OUD. While women have historically had lower rates of substance use and dependence, including heroin [120], this pattern is less clear in prescription opioids, with some studies reporting higher rates of recent [121] or regular use of prescription opioids [122] in women, but higher rates of abuse in men [123,124]. These higher rates of prescription use in women are worrying since, among individuals seeking treatment for opioid use disorder, women are more likely to report first obtaining opioids from a legitimate prescription from their doctor $[125,126]$, while men are more likely to first obtain from an illicit source [127]. Furthermore, as with other drugs of abuse, there is evidence of "telescoping" (i.e., a faster transition in women relative to men from initial to problematic substance use) in OUD $[128,129]$. Further, many large trials have 
found sex differences in clinical correlates at treatment entry, for example with some samples showing more co-morbid psychiatric conditions and more psychological distress in women [125, 127, 130].

Several lines of evidence also indicate sex-specific effects of opioid administration and withdrawal. For example, differential sex effects of methadone and naltrexone on testosterone [126] and cortisol [131] levels, respectively, have been reported. Furthermore, endogenous gonadal hormones impact opioid effects. For example, estrogens can diminish opioids' antinociceptive effects [132], there is evidence of interactions and crosstalk between opioid and estrogen receptors [133], and estrogens may impact the antinociceptive and rewarding effects of methadone through effects on methadone metabolism [134]. In addition, recent preclinical work suggests sex-specific effects of acute opioid withdrawal and subsequent opioid replacement (with methadone or buprenorphine) on regional brain metabolism within regions including the anterior cingulate, amygdala and striatum $[135,136]$. Thus, neuroimaging studies including equal numbers of male and female participants that are specifically powered to detect sex-specific effects are urgently needed in OUD.

Conclusions and recommendations for future work fMRI has the potential to provide critical insights into the pathophysiology and treatment of psychiatric disorders. However, this potential has yet to be fully leveraged within the context of OUD. Extant data from other substance use disorders (e.g., cocaine-use disorder) generally support the hypothesis that individual differences in brain function are related to differences in treatment responses [24, 28, 32, 58, 137], yet only a small number of studies have used fMRI to study treatment mechanisms relevant to OUD. Of these, most studies have conducted crosssectional comparisons of patients based on durations of abstinence or relapse status $[45,50,51,82]$. Thus, little is known about how individual differences in baseline neural function might contribute to variability in treatment responses to behavioral and medication treatments for OUD. Further research in this area is not only critically important to aid in the refinement of existing treatments based on known brain mechanisms, and to advance pathophysiological understanding of OUD, but will also pave the way for individual assignment of patients to specific treatments based on clinically relevant neuromarkers $[35,138,139]$. Similarly, longitudinal research assessing neural responses over the course of treatment is needed to identify brain-based mechanisms of behavior change within the context of the opioid epidemic. Furthermore, neuroimaging research also has the potential to identify novel treatment targets that could facilitate the development of innovative prevention and intervention approaches.

\section{ACKNOWLEDGEMENTS}

This work was support by NIDA grants T32 DA022975, K01DA039299, K01DA042988, and R21DA045969.

\section{ADDITIONAL INFORMATION}

Supplementary Information accompanies this paper at (https://doi.org/10.1038/ s41386-018-0232-4).

Competing interests: The authors declare no competing interests.

Publisher's note: Springer Nature remains neutral with regard to jurisdictional claims in published maps and institutional affiliations.

\section{REFERENCES}

1. Substance Abuse and Mental Health Services Administration Center for Behavioral Health Statistics and Quality. Treatment Episode Data Set (TEDS): 2002-
2012. Rockville, MD: Substance Abuse and Mental Health Services Administration; 2014.

2. Volkow ND, Frieden TR, Hyde PS, Cha SS. Medication-assisted therapies tackling the opioid-overdose epidemic. New Engl J Med. 2014;370:2063-6.

3. Palamar JJ, Shearston JA, Dawson EW, Mateu-Gelabert P, Ompad DC. Nonmedical opioid use and heroin use in a nationally representative sample of us high school seniors. Drug Alcohol Depend. 2016;158:132-8.

4. NIDA/SAMHSA Blending Initiative. "Buprenorphine Treatment for Young Adults." Retrieved 16 January 2016, from http://www.drugabuse.gov/sites/default/files/ files/BupTx_YngAdlts_Factsheet.pdf.

5. Center for Substance Abuse Treatment. Clinical Guidelines for the Use of Buprenorphine in the Treatment of Opioid Addiction. Rockville, MD: Substance Abuse and Mental Health Services Administration; 2004.

6. Maxwell JC, McCance-Katz EF. Indicators of buprenorphine and methadone use and abuse: what do we know? Am J Addict. 2010;19:73-88.

7. Subramaniam GA, Fishman MJ, Woody G. Treatment of opioid-dependent adolescents and young adults with buprenorphine. Curr Psychiatry Rep. 2009;11:360-3.

8. Woody GE, Poole SA, Subramaniam G, Dugosh K, Bogenschutz M, Abbott P, et al. Extended vs short-term buprenorphine-naloxone for treatment of opioidaddicted youth: a randomized trial. JAMA. 2008;300:2003-11.

9. Tkacz J, Severt J, Cacciola J, Ruetsch C. Compliance with buprenorphine medication-assisted treatment and relapse to opioid use. Am J Addict. 2012;21:55-62.

10. Hser Yl, Evans E, Huang D, Weiss R, Saxon A, Carroll KM, et al. Long-term outcomes after randomization to buprenorphine/naloxone versus methadone in a multi-site trial. Addiction. 2016;111:695-705.

11. Lee JD, Nunes EV Jr., Novo P, Bachrach K, Bailey GL, Bhatt S, et al. Comparative effectiveness of extended-release naltrexone versus buprenorphine-naloxone for opioid relapse prevention (X:BOT): a multicentre, open-label, randomised controlled trial. Lancet. 2018;391:309-18.

12. Schuman-Olivier Z, Weiss RD, Hoeppner BB, Borodovsky J, Albanese MJ. Emerging adult age status predicts poor buprenorphine treatment retention. J Subst Abus Treat. 2014;47:202-12.

13. Smyth BP, Fagan J, Kernan K. Outcome of heroin-dependent adolescents presenting for opiate substitution treatment. J Subst Abus Treat. 2012;42:35-44.

14. Taber M, Fibiger HC. Electrical stimulation of the medial prefrontal cortex increases dopamine release in the striatum. Neuropsychophamacol. 1993;9:271-5.

15. Volkow ND, Fowler JS, Wang G-J, Telang F, Logan J, Jayne M, et al. Cognitive control of drug craving inhibits brain reward regions in cocaine abusers. Neurolmage. 2010;49:2536-43.

16. Goldstein RZ, Volkow ND. Dysfunction of the prefrontal cortex in addiction: neuroimaging findings and clinical implications. Nat Rev Neurosci. 2011;12:652-69.

17. Kober $\mathrm{H}$, Mende-Siedlecki $\mathrm{P}$, Kross EF, Weber J, Mischel $\mathrm{W}$, Hart $\mathrm{CL}$, et al. Prefrontal-striatal pathway underlies cognitive regulation of craving. Proc Natl Acad Sci USA. 2010;107:14811-6.

18. D'Ardenne K, McClure SM, Nystrom LE, Cohen JD. BOLD responses reflecting dopaminergic signals in the human ventral tegmental area. Science. 2008:319:1264-7.

19. Everitt B, Robbins TW. Neural systems of reinforcement for drug addiction: from actions to habits to compulsion. Nat Neurosci. 2005;8:1481-9.

20. Schultz W, Dayan P, Montague RR. A neural substrate of prediction and reward. Science. 1997;275:1593-9.

21. Schultz W, Tremblay L, Hollerman JR. Reward processing in primate orbitofrontal cortex and basal ganglia. Cereb Cortex. 2000;10:272-84.

22. Garavan $H$, Weierstall K. The neurobiology of reward and cognitive control systems and their role in incentivizing health behavior. Prev Med. 2012;55: S17-23.

23. Koob GF, Volkow ND. Neurocircuitry of addiction. Neuropsychopharmacology. 2010;35:217-38.

24. Worhunsky PD, Stevens MC, Carroll KM, Rounsaville BJ, Calhoun VD, Pearlson $\mathrm{GD}$, et al. Functional brain networks associated with cognitive control, cocaine dependence, and treatment outcome. Psychol Addict Behav. 2013;27:477-88.

25. DeVito EE, Worhunsky PD, Carroll KM, Rounsaville BJ, Kober H, Potenza MN. A preliminary study of the neural effects of behavioral therapy for substance use disorders. Drug Alcohol Depend. 2012;122:228-35.

26. Luo SX, Martinez D, Carpenter KM, Slifstein M, Nunes EV. Multimodal predictive modeling of individual treatment outcome in cocaine dependence with combined neuroimaging and behavioral predictors. Drug Alcohol Depend. 2014;143:29-35.

27. Martinez D, Carpenter K, Liu F, Slifstein M, Broft A, Friedman A, et al. Imaging dopamine transmission in cocaine dependence: link between neurochemistry and response to treatment. Am J Psychiatry. 2011;168:634-41. 
28. Marhe R, Luijten $M$, van de Wetering $B J$, Smits $M$, Franken $\mathrm{IH}$. Individual differences in anterior cingulate activation associated with attentional bias predict cocaine use after treatment. Neuropsychopharmacol. 2013;38:1085-93.

29. Stewart JL, Connolly CG, May AC, Tapert SF, Wittmann M, Paulus MP. Cocaine dependent individuals with attenuated striatal activation during reinforcement learning are more susceptible to relapse. Psychiatry Res. 2014;223:129-39.

30. Stewart JL, Connolly CG, May AC, Tapert SF, Wittmann M, Paulus MP. Striatum and insula dysfunction during reinforcement learning differentiates abstinent and relapsed methamphetamine-dependent individuals. Addiction. 2014;109:460-71.

31. Yip SW, Potenza MN. Application of Research Domain Criteria to childhood and adolescent impulsive and addictive disorders: Implications for treatment. Clin Psychol Rev. 2018;64:41-56.

32. Moeller SJ, Paulus MP. Toward biomarkers of the addicted human brain: Using neuroimaging to predict relapse and sustained abstinence in substance use disorder. Prog Neuropsychopharmacol Biol Psychiatry. 2018;80(Pt B):143-54.

33. Potenza Marc N, Sofuoglu M, Carroll Kathleen M, Rounsaville Bruce J. Neuroscience of behavioral and pharmacological treatments for addictions. Neuron. 2011;69:695-712.

34. Ordonez Gallego A, Gonzalez Baron M, Espinosa Arranz E. Oxycodone: a pharmacological and clinical review. Clin Transl Oncol. 2007;9:298-307.

35. Yip SW, Carroll KM, Potenza MN. Translational Approaches to Addiction Treatment. In: Neuroimaging and Psychosocial Addiction Treatment: An Integrative Guide for Researchers and Clinicians. pp. 3-14 (eds Ewing SWF, Witkiewitz K, Filbey FM) (London: Palgrave Macmillan UK, 2015).

36. Cabrera EA, Wiers CE, Lindgren E, Miller G, Volkow ND, Wang G-J. Neuroimaging the effectiveness of substance use disorder treatments. J Neuroimmune Pharmacol. 2016;11:408-33.

37. Zilverstand A, Huang AS, Alia-Klein N, Goldstein RZ. Neuroimaging impaired response inhibition and salience attribution in human drug addiction: a systematic review. Neuron. 2018;98:886-903.

38. Fareed A, Kim J, Ketchen B, Kwak WJ, Wang D, Shongo-Hiango H, et al. Effect of heroin use on changes of brain functions as measured by functional magnetic resonance imaging, a systematic review. J Addictive Diseases. 2017;36:105-16.

39. Leong HF, Yuan Z. Resting-State Neuroimaging and Neuropsychological Findings in Opioid Use Disorder during Abstinence: A Review. Front Hum Neurosci. 2017;11:169.

40. Pandria N, Kovatsi L, Vivas AB, Bamidis PD. Resting-state Abnormalities in Heroin-dependent Individuals. Neuroscience. 2018;378:113-45.

41. Volkow ND, Boyle M. Neuroscience of addiction: relevance to prevention and treatment. Am J Psychiatry. 2018. https://doi.org/10.1176/appi.ajp.2018.17101174.

42. Koob GF, Volkow ND. Neurobiology of addiction: a neurocircuitry analysis. Lancet Psychiatry. 2016;3:760-73.

43. Walter M, Denier N, Gerber H, Schmid O, Lanz C, Brenneisen R, et al. Orbitofrontal response to drug-related stimuli after heroin administration. Addict Biol. 2015;20:570-9.

44. Wang AL, Elman I, Lowen SB, Blady SJ, Lynch KG, Hyatt JM, et al. Neural correlates of adherence to extended-release naltrexone pharmacotherapy in heroin dependence. Transl Psychiatry. 2015;5:e531.

45. Wang Y, Wang H, Li W, Zhu J, Gold MS, Zhang D, et al. Reduced responses to heroin-cue-induced craving in the dorsal striatum: effects of long-term methadone maintenance treatment. Neurosci Lett. 2014;581:120-4.

46. Langleben DD, Ruparel K, Elman I, Busch-Winokur S, Pratiwadi R, Loughead J, et al. Acute effect of methadone maintenance dose on brain FMRI response to heroin-related cues. Am J Psychiatry. 2008;165:390-4.

47. Langleben DD, Ruparel K, Elman I, Loughead JW, Busch EL, Cornish J, et al. Extended-release naltrexone modulates brain response to drug cues in abstinent heroin-dependent patients. Addict Biol. 2014;19:262-71.

48. Li Q, Li W, Wang H, Wang Y, Zhang Y, Zhu J, et al. Predicting subsequent relapse by drug-related cue-induced brain activation in heroin addiction: an eventrelated functional magnetic resonance imaging study. Addict Biol. 2015a;20:968-78.

49. Li Q, Wang Y, Zhang Y, Li W, Yang W, Zhu J, et al. Craving correlates with mesolimbic responses to heroin-related cues in short-term abstinence from heroin: an event-related fMRI study. Brain Res. 2012;1469:63-72.

50. Li Q, Wang Y, Zhang Y, Li W, Zhu J, Zheng Y, et al. Assessing cue-induced brain response as a function of abstinence duration in heroin-dependent individuals: an event-related fMRI study. PLoS ONE. 2013;8:e62911.

51. Lou M, Wang E, Shen Y, Wang J. Cue-elicited craving in heroin addicts at different abstinent time: an fMRI pilot study. Subst Use Misuse. 2012;47:631-9.

52. Mei W, Zhang JX, Xiao Z. Acute effects of sublingual buprenorphine on brain responses to heroin-related cues in early-abstinent heroin addicts: an uncontrolled trial. Neuroscience. 2010;170:808-15.
53. Zijlstra F, Veltman DJ, Booij J, van den Brink W, Franken IH. Neurobiological substrates of cue-elicited craving and anhedonia in recently abstinent opioiddependent males. Drug Alcohol Depend. 2009;99:183-92.

54. Filbey FM, Schacht JP, Myers US, Chavez RS, Hutchison KE. Marijuana craving in the brain. Proc Natl Acad Sci USA. 2009;106:13016-21.

55. Garavan H, Pankiewicz J, Bloom A, Cho J-K, Sperry L, Ross TJ, Salmeron BJ, Risinger R, Kelley D, Stein EA. Cue-induced cocaine craving: Neuroanatomical specificity for drug users and drug stimuli. Am J Psychiatry. 2000;157:1789-98.

56. Balodis IM, Potenza MN. Anticipatory reward processing in addicted populations: a focus on the monetary incentive delay task. Biol Psychiatry. 2015;77:434-44.

57. Gradin VB, Baldacchino A, Balfour D, Matthews K, Steele JD. Abnormal brain activity during a reward and loss task in opiate-dependent patients receiving methadone maintenance therapy. Neuropsychopharmacology. 2014;39:885-94.

58. Yip SW, DeVito EE, Kober H, Worhunsky PD, Carroll KM, Potenza MN. Anticipatory reward processing among cocaine-dependent individuals with and without concurrent methadone-maintenance treatment: Relationship to treatment response. Drug Alcohol Depend. 2016;166:134-42.

59. Luijten M, Schellekens AF, Kuhn S, Machielse MW, Sescousse G: Disruption of Reward Processing in Addiction: An Image-Based Meta-analysis of Functional Magnetic Resonance Imaging Studies. JAMA Psychiatry. 2017;74:387-98.

60. Wilcox CE, Pommy JM, Adinoff B. Neural circuitry of impaired emotion regulation in substance use disorders. Am J Psychiatry. 2016;173:344-61.

61. Yip SW, Gross JJ, Chawla M, Ma SS, Shi XH, Liu L, et al. Is neural processing of negative stimuli altered in addiction independent of drug effects? findings from drug-naive youth with internet gaming disorder. Neuropsychopharmacology. 2018;43:1364-72.

62. Fox HC, Axelrod SR, Paliwal P, Sleeper J, Sinha R. Difficulties in emotion regulation and impulse control during cocaine abstinence. Drug Alcohol Depend. 2007;89:298-301.

63. Wang ZX, Zhang JX, Wu QL, Liu N, Hu XP, Chan RC, et al. Alterations in the processing of non-drug-related affective stimuli in abstinent heroin addicts. Neuroimage. 2010;49:971-6.

64. Schmidt A, Borgwardt S, Gerber H, Wiesbeck GA, Schmid O, Riecher-Rossler A, et al. Acute effects of heroin on negative emotional processing: relation of amygdala activity and stress-related responses. Biol Psychiatry. 2014;76:289-96.

65. Schmidt A, Walter M, Gerber $H$, Seifritz $E$, Brenneisen $R$, Wiesbeck GA, et al Normalizing effect of heroin maintenance treatment on stress-induced brain connectivity. Brain. 2015b;138:217-28.

66. Volkow ND, Wang GJ, Tomasi D, Baler RD. Unbalanced neuronal circuits in addiction. Curr Opin Neurobiol. 2013;23:639-48.

67. Everitt BJ, Robbins TW. Drug addiction: updating actions to habits to compulsions ten years on. Annu Rev Psychol. 2016;67:23-50.

68. Steele VR, Claus ED, Aharoni E, Harenski C, Calhoun VD, Pearlson G, et al. A large scale $(\mathrm{N}=102)$ functional neuroimaging study of error processing in a Go/NoGo task. Behav Brain Res. 2014;268:127-38.

69. Fu LP, Bi GH, Zou ZT, Wang Y, Ye EM, Ma L, et al. Impaired response inhibition function in abstinent heroin dependents: an fMRI study. Neurosci Lett. 2008;438:322-6.

70. Schmidt A, Walter M, Gerber H, Schmid O, Smieskova R, Bendfeldt $K$, et al. Inferior frontal cortex modulation with an acute dose of heroin during cognitive control. Neuropsychopharmacology. 2013;38:2231-9.

71. Yucel M, Lubman DI, Harrison BJ, Fornito A, Allen NB, Wellard RM, et al. A combined spectroscopic and functional MRI investigation of the dorsal anterior cingulate region in opiate addiction. Mol Psychiatry. 2007;12:691-702. 611

72. Chang H, Li W, Li Q, Chen J, Zhu J, Ye J, et al. Regional homogeneity changes between heroin relapse and non-relapse patients under methadone maintenance treatment: a resting-state fMRI study. BMC Neurology. 2016;16:145.

73. Wang PW, Lin HC, Liu GC, Yang YH, Ko CH, Yen CF. Abnormal interhemispheric resting state functional connectivity of the insula in heroin users under methadone maintenance treatment. Psychiatry Res Neuroimaging. 2016;255:9-14.

74. Wang W, Wang YR, Qin W, Yuan K, Tian J, Li Q, et al. Changes in functional connectivity of ventral anterior cingulate cortex in heroin abusers. Chin Med J. 2010;123:1582-8.

75. Wang Y, Zhu J, Li Q, Li W, Wu N, Zheng Y, et al. Altered fronto-striatal and frontocerebellar circuits in heroin-dependent individuals: a resting-state FMRI study. PLoS ONE. 2013;8:e58098.

76. Xie C, Shao Y, Fu L, Goveas J, Ye E, Li W, et al. Identification of hyperactive intrinsic amygdala network connectivity associated with impulsivity in abstinent heroin addicts. Behav Brain Res. 2011;216:639-46.

77. Xie C, Shao Y, Ma L, Zhai T, Ye E, Fu L, et al. Imbalanced functional link between valuation networks in abstinent heroin-dependent subjects. Mol Psychiatry. 2014;19:10-12. 
78. Zhang Y, Gong J, Xie C, Ye EM, Jin X, Song H, et al. Alterations in brain connectivity in three sub-regions of the anterior cingulate cortex in heroindependent individuals: evidence from resting state fMRI. Neuroscience. 2015;284:998-1010.

79. Jiang G, Wen X, Qiu Y, Zhang R, Wang J, Li M, et al. Disrupted topological organization in whole-brain functional networks of heroin-dependent individuals: a resting-state fMRI study. PLoS ONE. 2013;8:e82715.

80. Jiang GH, Qiu YW, Zhang XL, Han LJ, Lv XF, Li LM, et al. Amplitude low-frequency oscillation abnormalities in the heroin users: a resting state fMRI study. Neuroimage. 2011;57:149-54.

81. Li Q, Li Z, Li W, Zhang Y, Wang Y, Zhu J, et al. Disrupted default mode network and basal craving in male heroin-dependent individuals: a resting-state fMRI study. J Clin Psychiatry. 2016;77:e1211-7.

82. Li W, Li Q, Wang D, Xiao W, Liu K, Shi L, et al. Dysfunctional default mode network in methadone treated patients who have a higher heroin relapse risk. Sci Rep. 2015;5:15181.

83. Liu J, Qin W, Yuan K, Li J, Wang W, Li Q, et al. Interaction between dysfunctional connectivity at rest and heroin cues-induced brain responses in male abstinent heroin-dependent individuals. PLoS ONE. 2011;6:e23098.

84. Qiu YW, Jiang GH, Su HH, Lv XF, Ma XF, Tian JZ, et al. Short-term UROD treatment on cerebral function in codeine-containing cough syrups dependent male individuals. Eur Radiol. 2016;26:2964-73.

85. Schmidt A, Denier N, Magon S, Radue EW, Huber CG, Riecher-Rossler A, et al. Increased functional connectivity in the resting-state basal ganglia network after acute heroin substitution. Transl Psychiatry. 2015;5:e533.

86. Amaral LA, Scala A, Barthelemy M, Stanley HE. Classes of small-world networks. Proc Natl Acad Sci USA. 2000;97:11149-52.

87. Cicero TJ, Ellis MS, Surratt HL, Kurtz SP. The changing face of heroin use in the United States: a retrospective analysis of the past 50 years. JAMA Psychiatry. 2014;71:821-6.

88. Taylor JJ, Borckardt JJ, Canterberry M, Li X, Hanlon CA, Brown TR, et al. Naloxone-reversible modulation of pain circuitry by left prefrontal rTMS. Neuropsychopharmacology. 2013;38:1189-97.

89. Upadhyay J, Anderson J, Baumgartner R, Coimbra A, Schwarz AJ, Pendse G, et al. Modulation of CNS pain circuitry by intravenous and sublingual doses of buprenorphine. Neuroimage. 2012;59:3762-73.

90. Upadhyay J, Anderson J, Schwarz AJ, Coimbra A, Baumgartner R, Pendse G, et al. Imaging drugs with and without clinical analgesic efficacy. Neuropsychopharmacology. 2011;36:2659-73.

91. Wardle MC, Fitzgerald DA, Angstadt M, Rabinak CA, de Wit H, Phan KL. Effects of oxycodone on brain responses to emotional images. Psychopharmacology. 2014;231:4403-15.

92. Chu LF, Lin JC, Clemenson A, Encisco E, Sun J, Hoang D, et al. Acute opioid withdrawal is associated with increased neural activity in reward-processing centers in healthy men: a functional magnetic resonance imaging study. Drug Alcohol Depend. 2015;153:314-22.

93. Atlas LY, Whittington RA, Lindquist MA, Wielgosz J, Sonty N, Wager TD. Dissociable influences of opiates and expectations on pain. J Neurosci. 2012;32:8053-64.

94. Gear R, Becerra L, Upadhyay J, Bishop J, Wallin D, Pendse G, et al. Pain facilitation brain regions activated by nalbuphine are revealed by pharmacological fMRI. PLoS ONE. 2013;8:e50169.

95. Gorka SM, Fitzgerald DA, de Wit H, Angstadt M, Phan KL. Opioid modulation of resting-state anterior cingulate cortex functional connectivity. J Psychopharmacol. 2014;28:1115-24.

96. Hayen A, Wanigasekera V, Faull OK, Campbell SF, Garry PS, Raby SJM, et al. Opioid suppression of conditioned anticipatory brain responses to breathlessness. Neuroimage. 2017;150:383-94.

97. Murray E, Brouwer S, McCutcheon R, Harmer CJ, Cowen PJ, McCabe C. Opposing neural effects of naltrexone on food reward and aversion: implications for the treatment of obesity. Psychopharmacology. 2014;231:4323-35.

98. Oertel BG, Preibisch C, Wallenhorst T, Hummel T, Geisslinger G, Lanfermann H, et al. Differential opioid action on sensory and affective cerebral pain processing. Clin Pharmacol Ther. 2008;83:577-88.

99. Robinson LF, Atlas LY, Wager TD. Dynamic functional connectivity using statebased dynamic community structure: method and application to opioid analgesia. Neuroimage. 2015;108:274-91.

100. Borras MC, Becerra L, Ploghaus A, Gostic JM, DaSilva A, Gonzalez RG, et al. fMRI measurement of CNS responses to naloxone infusion and subsequent mild noxious thermal stimuli in healthy volunteers. J Neurophysiol. 2004;91:2723-33.

101. Lanz S, Seifert F, Maihofner C. Brain activity associated with pain, hyperalgesia and allodynia: an ALE meta-analysis. J Neural Transm. 2011;118:1139-54.

102. Seifert F, Jungfer I, Schmelz M, Maihofner C. Representation of UV-B-induced thermal and mechanical hyperalgesia in the human brain: a functional MRI study. Hum Brain Mapp. 2008;29:1327-42.
103. Wiers CE, Stelzel C, Gladwin TE, Park SQ, Pawelczack S, Gawron CK, et al. Effects of cognitive bias modification training on neural alcohol cue reactivity in alcohol dependence. Am J Psychiatry. 2015;172:335-43.

104. Hartwell KJ, Hanlon CA, Li X, Borckardt JJ, Canterberry M, Prisciandaro JJ, et al. Individualized real-time fMRI neurofeedback to attenuate craving in nicotinedependent smokers. J Psychiatry Neurosci. 2016:41:48-55.

105. Zuo XN, Xu T, Jiang L, Yang Z, Cao XY, He Y, et al. Toward reliable characterization of functional homogeneity in the human brain: preprocessing, scan duration, imaging resolution and computational space. Neuroimage. 2013;65:374-86.

106. Laumann TO, Gordon EM, Adeyemo B, Snyder AZ, Joo SJ, Chen MY, et al. Functional system and areal organization of a highly sampled individual human brain. Neuron. 2015;87:657-70.

107. Nichols TE, Das S, Eickhoff SB, Evans AC, Glatard T, Hanke M, et al. Best practices in data analysis and sharing in neuroimaging using MRI. Nat Neurosci. 2017;20:299-303.

108. Noble S, Spann MN, Tokoglu F, Shen X, Constable RT, Scheinost D. Influences on the test-retest reliability of functional connectivity MRI and its relationship with behavioral utility. Cereb Cortex. 2017;27:5415-29.

109. Poldrack RA, Barch DM, Mitchell JP, Wager TD, Wagner AD, Devlin JT, et al. Toward open sharing of task-based fMRI data: the OpenfMRI project. Front Neuroinform. 2013;7:12.

110. Biswal BB, Mennes M, Zuo XN, Gohel S, Kelly C, Smith SM, et al. Toward discovery science of human brain function. Proc Natl Acad Sci USA. 2010;107:4734-9.

111. Power JD, Mitra A, Laumann TO, Snyder AZ, Schlaggar BL, Petersen SE. Methods to detect, characterize, and remove motion artifact in resting state fMRI. Neuroimage. 2014;84:320-41.

112. Scheinost $D$, Papademetris $X$, Constable RT. The impact of image smoothness on intrinsic functional connectivity and head motion confounds. Neuroimage. 2014:95:13-21.

113. Hser Yl, Mooney L, Saxon AJ, Miotto K, Bell DS, Huang D. Chronic pain among patients with opioid use disorder: results from electronic health records data. J Subst Abus Treat. 2017;77:26-30.

114. Jo HJ, Saad ZS, Simmons WK, Milbury LA, Cox RW. Mapping sources of correlation in resting state FMRI, with artifact detection and removal. Neuroimage. 2010;52:571-82.

115. Khalili-Mahani N, van Osch MJ, de Rooij M, Beckmann CF, van Buchem MA, Dahan $A$, et al. Spatial heterogeneity of the relation between resting-state connectivity and blood flow: an important consideration for pharmacological studies. Hum Brain Mapp. 2014;35:929-42.

116. Liu TT. Neurovascular factors in resting-state functional MRI. Neuroimage. 2013;80:339-48.

117. Qiu M, Scheinost D, Ramani R, Constable RT. Multi-modal analysis of functional connectivity and cerebral blood flow reveals shared and unique effects of propofol in large-scale brain networks. Neurolmage. 2017;148:130-40.

118. Muhuri $P$, Gfroerer J, Davies M. Associations of nonmedical pain reliever use and initiation of heroin use in the United States. SAMHSA. 2013. Available from https://www.samhsa.gov/data/sites/default/files/DR006/DR006/nonmedicalpain-reliever-use-2013.htm (accessed 22 April 2017).

119. Wetherington CL. Sex-gender differences in drug abuse: a shift in the burden of proof? Exp Clin Psychopharmacol. 2007;15:411-7.

120. SAMHSA. Results from the 2010 National Survey on Drug Use and Health: summary of findings. Rockville, MD: Substance Abuse and Mental Health Services Administration; 2011.

121. Serdarevic M, Striley CW, Cottler LB. Sex differences in prescription opioid use. Curr Opin Psychiatry. 2017;30:238-46.

122. Parsells Kelly J, Cook SF, Kaufman DW, Anderson T, Rosenberg L, Mitchell AA. Prevalence and characteristics of opioid use in the US adult population. Pain. 2008;138:507-13.

123. Gasior M, Bond M, Malamut R. Routes of abuse of prescription opioid analgesics: a review and assessment of the potential impact of abuse-deterrent formulations. Postgrad Med. 2016;128:85-96.

124. Osborne V, Serdarevic M, Crooke H, Striley C, Cottler LB. Non-medical opioid use in youth: Gender differences in risk factors and prevalence. Addict Behav. 2017:72:114-9.

125. McHugh RK, Devito EE, Dodd D, Carroll KM, Potter JS, Greenfield SF, et al. Gender differences in a clinical trial for prescription opioid dependence. J Subst Abus Treat. 2013;45:38-43.

126. Bawor M, Bami H, Dennis BB, Plater C, Worster A, Varenbut M, et al. Testosterone suppression in opioid users: a systematic review and meta-analysis. Drug Alcohol Depend. 2015;149:1-9.

127. Back SE, Payne RL, Simpson AN, Brady KT. Gender and prescription opioids: findings from the National Survey on Drug Use and Health. Addict Behav. 2010;35:1001-7. 
Can neuroimaging help combat the opioid epidemic? A systematic review of... $\mathrm{H}$ Moningka et al.

128. Back SE, Lawson KM, Singleton LM, Brady KT. Characteristics and correlates of men and women with prescription opioid dependence. Addict Behav. 2011;36:829-34.

129. Hernandez-Avila CA, Rounsaville BJ, Kranzler HR. Opioid-, cannabis- and alcoholdependent women show more rapid progression to substance abuse treatment. Drug Alcohol Depend. 2004;74:265-72.

130. Manubay J, Davidson J, Vosburg S, Jones J, Comer S, Sullivan M. Sex differences among opioid-abusing patients with chronic pain in a clinical trial. J Addict Med. 2015;9:46-52.

131. Roche DJ, King AC. Sex differences in acute hormonal and subjective response to naltrexone: The impact of menstrual cycle phase. Psychoneuroendocrinology. 2015;52:59-71.

132. Loyd DR, Murphy AZ. The role of the periaqueductal gray in the modulation of pain in males and females: are the anatomy and physiology really that different? Neural Plast. 2009;2009:462879.

133. Lee CW, Ho K. Sex differences in opioid analgesia and addiction: interactions among opioid receptors and estrogen receptors. Molecular Pain. 2013;9:45.
134. Chiang YC, Wang RY, Huang CL, Chen SH, Ho WJ, Lane HY, et al. Reduced dosing and liability in methadone maintenance treatment by targeting oestrogen signal for morphine addiction. J Cell Mol Med. 2017;21:3552-64.

135. Santoro GC, Carrion J, Dewey SL. Imaging Sex Differences in Regional Brain Metabolism during Acute Opioid Withdrawal. J Alcohol Drug Depend. 2017;5:262.

136. Santoro GC, Carrion J, Patel K, Vilchez C, Veith J, Brodie JD, et al. Sex differences in regional brain glucose metabolism following opioid withdrawal and replacement. Neuropsychopharmacology. 2017;42:1841-9.

137. Balodis IM, Kober H, Worhunsky PD, Stevens MC, Pearlson GD, Carroll KM, et al. Neurofunctional reward processing changes in cocaine dependence during recovery. Neuropsychopharmacology. 2016;41:2112-21.

138. Whitfield-Gabrieli S, Ghosh SS, Nieto-Castanon A, Saygin Z, Doehrmann O, Chai $\mathrm{XJ}$, et al. Brain connectomics predict response to treatment in social anxiety disorder. Mol Psychiatry. 2016;21:680-5.

139. Chung T, Noronha A, Carroll KM, Potenza MN, Hutchison K, Calhoun VD, et al. Brain mechanisms of change in addictions treatment: models, methods, and emerging findings. Curr Addict Rep. 2016;3:332-42. 